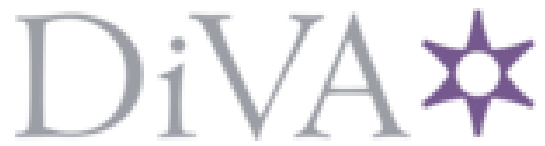

http://www.diva-portal.org

Preprint

This is the submitted version of a paper published in Carbon.

Citation for the original published paper (version of record):

Talyzin, A., Mercier, G., Klechikov, A., Hedenström, M., Johnels, D. et al. (2017)

Brodie vs Hummers graphite oxides for preparation of multi-layered materials

Carbon, 115: 430-440

https://doi.org/10.1016/j.carbon.2016.12.097

Access to the published version may require subscription.

N.B. When citing this work, cite the original published paper.

Permanent link to this version:

http://urn.kb.se/resolve?urn=urn:nbn:se:umu:diva-130949 


\title{
Brodie vs Hummers graphite oxides for preparation of multi-layered materials
}

Alexandr V.Talyzin, ${ }^{* a}$ Guillaume Mercier, ${ }^{\mathrm{a}}$ Alexey Klechikov, ${ }^{\mathrm{a}}$ Mattias Hedenström ${ }^{\mathrm{b}}$, Dan Johnels ${ }^{\mathrm{b}}$, Di Wei ${ }^{\mathrm{c}}$, Darryl Cotton ${ }^{\mathrm{c}}$, Andreas Opitz, ${ }^{\mathrm{d}}$ Ellen Moons ${ }^{\mathrm{e}}$

${ }^{a}$ Department of Physics, Umeå University, SE-901 87 Umeå, Sweden.

${ }^{b}$ Department of Chemistry, Umeå University, SE-901 87 Umeå, Sweden.

${ }^{c}$ Nokia Technologies, Broers Building, 21 JJ Thomson Avenue, Cambridge CB3 OFA, UK

${ }^{d}$ Department of Physics, Humboldt-Universität zu Berlin, 12489 Berlin, Germany

${ }^{e}$ Department of Engineering and Physics, Karlstad University, 65188 Karlstad Sweden

*Corresponding author. E-mail: alexandr.talyzin@umu.se

\begin{abstract}
Graphite oxides synthesized by one and two step Brodie oxidation (BGO) and Hummers (HGO) methods were analysed by a variety of characterization methods in order to evaluate the reasons behind the difference in their properties. It is found that the Brodie method results in a higher relative amount of hydroxyl groups and a more homogeneous overall distribution of functional groups over the planar surface of the graphene oxide flakes. The higher number of carbonyl and carboxyl groups in HGO, detected by several methods, including XPS, NMR and FTIR, unavoidably results in defects of the graphene "skeleton", holes and overall disruption of the carbon-carbon bond network, stronger deviation from planar flake shape and poor ordering of the graphene oxide layers. It is also suggested that functional groups in HGO are less homogeneously distributed over the flake surface, forming some nanometer-sized graphene areas. The presence of differently oxidized areas on the GO surface results in inhomogeneous solvation and hydration of $\mathrm{HGO}$ and effects of inter- and intrastratification. The proposed interpretation of the data explains the higher mechanical strength of multi-layered BGO membranes/papers, which are also less affected by humidity changes, thus providing an example of a membrane property superior to that of HGO.
\end{abstract}




\section{Introduction}

Graphite oxides (GO) are widely used as precursor for the preparation of graphene oxide dispersions in water and other solvents [1]. Graphene oxide dispersions can then be deposited into various multilayered graphene oxide structures, chemically modified using solution-based methods, or reduced to prepare various graphene-related materials for multifunctional applications. For example, simple evaporation, filtration or spin-coating procedures have been used for thin film preparation [2-5] and freestanding foils $[1,6]$. These GO foils of micrometer thickness are named either as papers [6-8], or membranes [1, 9-13] depending on their intended applications. Unusual vapor, gas and liquid permeation properties of GO membranes have recently attracted a lot of attention[13-16], whereas GO papers have been reported to exhibit excellent mechanical properties [6].

It is known that GO papers and membranes inherit some properties from graphite oxides, e.g. very similar distance between graphene oxide sheets in the dried state and ability to swell in polar solvents [6, 10]. Many studies have also been aimed on reduction of graphite/graphene oxides into graphene, e.g.[17] This subject is out of scope of our study while we focus on difference in properties of multilayered graphene oxide materials.

Our recent studies revealed significant differences in hydration and solvation properties of GO membranes and the precursor graphite oxides. For example, graphite oxides can be intercalated equally well by both water and alcohols (methanol and ethanol) with amounts corresponding to several monolayers, the amount of intercalated solvent strongly depending on variations temperature and pressure conditions [18, 19]. In contrast, the insertion of methanol and ethanol in the GO membrane structure is limited to only one monolayer and shows no change upon temperature variations [20]. Recent results demonstrate that swelling of GO membranes can be nearly identical to swelling of the precursor graphite oxides for certain solvents (e.g. water) and rather different for others (e.g. methanol, acetonitrile, dioxolane) [21]. Swelling of GO membranes in various polar solvents is closely connected to their permeation properties, which exhibit certain selectivity for binary 
mixtures [20]. For example, fast water permeation through GO membranes and decreased permeability by alcohols was reported in several studies [13, 22]. Quantitative evaluation of selectivity in water/ethanol absorption by GO films was also performed using neutron reflectivity [23].

Most of the recent studies have been performed using graphite oxides prepared by different variations of the Hummers method [24]. In many cases the results are considered general for "graphite oxide". However, it is known that GO prepared by other methods, e.g. the Brodie method [25], exhibit remarkably different properties compared to Hummers GO (HGO). For example, Brodie graphite oxides (BGO) exhibit 50-100 degrees higher temperature of exfoliation [26, 27], phase transition between one and two layered solvate phases [28, 29] absent in HGO [19], selective intercalation of methanol or ethanol from binary mixtures with water [30]. The nature of the difference between the Brodie and Hummers graphite oxides remains poorly understood and only few studies are available on this subject [27, 31, 32]. It should be noted that a quantitative estimation for the relative numbers of various functional groups using reactions of GO with various chemicals was available for HGO already in 1960-s reporting hydroxyls and ether groups as the two most abundant ones with carbonyls, enols and carboxyls present in smaller amounts [33].

Considering the strong progress in the field over the past few years and a lot of new accumulated results, it is necessary to re-analyze the reasons behind the difference between graphite oxides produced by Brodie and Hummers methods. The relations between important properties of GO and, e.g., degree of oxidation and type of functionalization remain to be poorly understood and require clarification.

Brodie synthesis is usually performed using several oxidation steps, which results in materials with a different degree of oxidation after each step [34]. However, many properties of BGO have never been studied as a function of oxidation degree. For example, swelling in polar solvents and its temperature dependence were studied mostly on one type of highly oxidized samples [19, 28, 30, 35-38].

Very few studies of GO membranes prepared using Brodie GO are available at the moment [20]. Therefore, there is a strong interest in testing Brodie graphite oxide for the preparation of multilayered GO materials and in comparing their properties with Hummers GO membranes.

In this study we compare the properties of Brodie graphite oxides prepared using one and two oxidation steps. We also report superior mechanical properties of 
graphene oxide paper/membranes prepared using Brodie graphite oxide, as compared to Hummers GO. The nature of the difference between Brodie and Hummers graphite oxides and multilayered materials prepared using their aqueous dispersions is analyzed using a variety of methods: NEXAFS, NMR, FTIR and TGA.

\section{Experimental}

Graphite oxide powder samples were synthesized using the original Brodie procedure [25] and Hummers method (HGO1) [24]. Graphite samples supplied by Alfa Aesar (natural flake, 325 mesh, 99.8\%) were used for Hummers GO synthesis, details of procedure are available elsewhere.[39] A second sample of Hummers graphite oxide was purchased from ACS Materials (HGO2). The same type of commercial HGO was characterized in several of our previous studies [19, 20, 27]. For preparation of membranes and mechanical tests we used precursor graphite oxide prepared similarly to HGO1 but from different synthesis batch (HGO3).

Brodie oxidation was performed using $5 \mathrm{~g}$ small flake graphite (Graphexel, <200 $\mu \mathrm{m}$ ). It was mixed with 42,5g sodium chlorate, placed in an ice bath and $30 \mathrm{ml}$ of fuming nitric acid was added dropwise over $\sim 1$ hour time under continuous stirring. The mixture was continuously stirred for about 12 hours at ambient temperature and then heated to $60^{\circ} \mathrm{C}$ for 8 hours. After repeated washing with deionized water and $10 \% \mathrm{HCl}$ solution the paste was freeze-dried to get a brown colored powder (BGO1). Part of this powder was used to repeat the oxidation procedure (step 2 oxidation), which yielded a light yellow colored powder (BGO2). The only difference compared to the original Brodie procedure was the continuous stirring of the reaction paste. However, this small improvement allowed us to obtain a homogeneous and fully oxidized sample, free from unreacted graphite, already after one oxidation step.

The oxidation state of GO powders was verified using XPS. This method involves high vacuum conditions and samples are efficiently dried from residual water to yield correct $\mathrm{C} / \mathrm{O}$ ratio (atomic percent). Brodie synthesis samples showed $\mathrm{C} / \mathrm{O}=3.4$ and $\mathrm{C} / \mathrm{O}=2.7$ for $\mathrm{BGO} 1$ and BGO2 samples, respectively. The BGO2 sample is only slightly less oxidized compared to materials prepared using the Hummers method HGO1 and HGO2 samples $\mathrm{C} / \mathrm{O}=2.31$ and $\mathrm{C} / \mathrm{O}=2.5$, respectively. The XPS analysis also shows different impurities for BGO and HGO, as expected from the synthesis procedure. The Hummers method uses sulphuric acid and sulphur is always found in this type of GO, $0.76 \%$ in HGO1 and $0.66 \%$ in HGO2. The sulphur impurity most likely originates from sulphate anions and $\sim 3 \%$ of oxygen is likely to 
originate from these impurities. Correcting the $\mathrm{C} / \mathrm{O}$ value to exclude oxygen originating from this impurity provided $\mathrm{C} / \mathrm{O}=2.57$ for $\mathrm{HGO} 1$ and $\mathrm{C} / \mathrm{O}=2.71$ for $\mathrm{HGO}$. All samples also show minor impurities of nitrogen (up to $0.7 \%$ ) and chlorine $(0.3 \%)$.

Water dispersions of HGO samples were prepared using mild sonication for about 10-12 hours followed by centrifugation for 1-2 hours. The BGO2 dispersion was prepared by adding $\mathrm{NaOH}(0.01 \mathrm{M})$ since this type of $\mathrm{GO}$ does not get dispersed in pure water even after prolonged sonication. The multilayered membrane/paper samples were prepared by vacuum filtration of solutions through alumina membranes (Anodisc 25, $0.2 \mathrm{~mm}$, diameter: 25 and 45 $\mathrm{mm}$ from Whatman $\mathrm{GmbH}$ ). Finally, membranes were air dried directly on alumina filters and then separated from the support. The free standing membranes were air exposed for minimum 3 weeks prior to mechanical tests as it is known from our earlier experiments that water is very slowly removed from the multilayered samples [20].

NEXAFS spectra of $\mathrm{BGO} 2$ and $\mathrm{HGO} 2$ powders and thin films were recorded at beamline D1011 of the National Laboratory for Synchrotron Radiation (MAX-IV) in Lund, Sweden. Using polarized monochromatic X-rays, incident at an angle of $55^{\circ}$ with respect to the sample surface, NEXAFS spectra were collected both near the C1s absorption edge (photon energy 276-327 eV) and near the O1s edge (photon energy range 520-570 eV). Total electron yield (TEY) spectra were obtained by measuring the sample drain current. Angular resolved NEXAFS of $\mathrm{HGO} 2$ and $\mathrm{BGO} 2$ films drop-casted on $\mathrm{Si}$ wafers were measured at the $\mathrm{C} 1 \mathrm{~s}$ edge.

Reference spectra were recorded in TEY mode of a gold coated mica sample (Georg Albert, PVD-Beschichtungen) that had been cleaned in-situ by sputtering with argon, and all NEXAFS spectra were divided by the gold spectrum and normalized in the high photon energy region [40]. The photon energy scale was calibrated using the position of the exciton resonance at $291.65 \mathrm{eV}$ of highly ordered pyrolytic graphite (HOPG) as an energy reference [41].

Structural characterization of GO was performed using a Siemens 5000 diffractometer with $\mathrm{CuK}_{\alpha}$ radiation and using synchrotron radiation X-ray diffraction (XRD) at beamline I711 of the National Laboratory for Synchrotron Radiation (MAX-IV) in Lund, Sweden. XRD images were collected from powder samples loaded in glass capillaries, in some experiments with excess amounts of solvents, in transmission geometry. The samples of GO/solvent were also cooled down with 1-3 degrees per min ramp using an Oxford Cryosystems (CryoStream $700+)$ cooler with XRD images recorded with $\sim 2-3$ degree steps. The radiation wavelength 
was calibrated using a LaB6 standard $(\lambda=0.98987 \AA$ ). Fit2D software was used to integrate the diffraction images into diffraction patterns.

[42]

For mechanical tests the larger membrane discs were cut to $\sim 10 \mathrm{~mm}$ wide stripes and tested using a dynamic mechanical analyzer (DMA Q800), which utilizes non-contact, linear drive technology to provide precise control of stress, and air bearings for low friction support. Strain is measured using optical encoder technology that provides unmatched sensitivity and resolution. Membranes prepared under similar deposition conditions and with similar thickness of $\sim 4-5 \mu \mathrm{m}$ were used for mechanical tests in order to avoid thickness-related effects reported for GO papers.[43] The thickness was determined using digital micrometer and verified by SEM images taken from edge regions. As a reference we used common types of paper, (A4 cellulose based printer paper with $0.04 \mathrm{~mm}$ thickness) and elastic paper ("'Fisherbrand"TM Lab Wipes" $0.3 \mathrm{~mm}$ thickness). The values of the Young's modulus were calculated by the testing machine with fixed sample strain range of $0.1 \%-0.2 \%$."

Proton-decoupled ${ }^{13} \mathrm{C}$ NMR spectra were recorded on a Bruker $500 \mathrm{MHz}$ Avance III spectrometer equipped with a $4 \mathrm{~mm}$ MAS probe and using a spin-rate of $12 \mathrm{kHz} .7500$ scans were accumulated for each spectrum with a relaxation delay of $10 \mathrm{~s}$. Spectra were processed using Topspin 3.2 (Bruker Biospin, Germany) and a Gaussian window function with $\mathrm{lb}=-10$ $\mathrm{Hz}$ and $\mathrm{gb}=0.01$ was used.

\section{Results}

\subsection{Structure and swelling of Brodie vs Hummers GO}

The BGO sample synthesized for this study showed all typical features earlier reported for that type of material. For example, XRD data recorded at ambient conditions gives $\mathrm{d}(001)=$ 6.4-6.9 $\AA$ value, depending on ambient humidity levels. It is interesting to note that even after one oxidation step we achieved a complete transformation of the precursor graphite into graphite oxide as it is evidenced by the absence of peaks from precursor graphite in XRD.

Complete oxidation also manifests in the swelling of the BGO1 in water and alcohols. Both BGO1 and BGO2 samples exhibited typical phase transitions related in liquid methanol to insertion/de-insertion of solvent layer. That type of phase transitions was reported in our earlier studies for BGO immersed in methanol and ethanol,[28, 30] as well as in several other solvents (e.g. acetone, acetonitrile, DMF).[29, 44] Surprisingly, the difference between structure and swelling properties of $\mathrm{BGO} 1$ and $\mathrm{BGO} 2$ is rather small. For example, the 
$\mathrm{d}(001)=8.93 \AA$ and $\mathrm{d}(001)=9.05 \AA$ are found for powder immersed in excess of liquid methanol for BGO1 and BGO2 oxidations, respectively. The difference between inter-layer distances measured for BGO1 and BGO2 is only about $0.1 \AA$ despite significant difference in oxidation degree $(\mathrm{C} / \mathrm{O}=3.4$ and $\mathrm{C} / \mathrm{O}=2.7$ for $\mathrm{BGO} 1$ and $\mathrm{BGO} 2$, respectively). It is interesting that diffraction peaks of BGO become stronger and less broad (almost twice smaller FWHM) in the methanol -swelled state compared to solvent free powder. In contrast, HGO samples always show weaker and broader peaks in the swelled state.
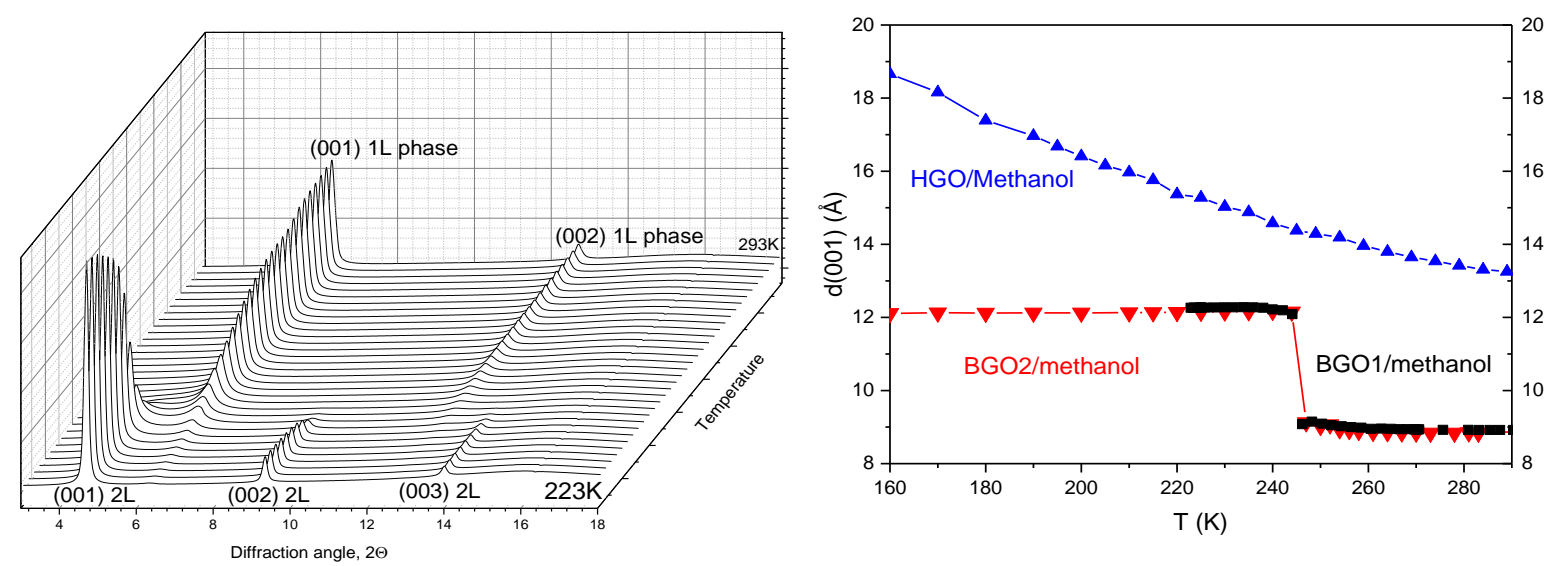

a)

b)

Figure 1. a) XRD patterns recorded from BGO1 sample in liquids methanol upon cooling, indexing provided for one -layered solvate (1L) phase at ambient temperature and for low temperature twolayered (2L) solvate phase; b) Inter-layer distance, $\mathrm{d}(001)$ plotted as a function of temperature for samples of BGO1 $\boldsymbol{\sim}$ and earlier studied samples of HGO1[19] $\boldsymbol{\Delta}$ and sample similar to BGO2 $\boldsymbol{\nabla}$, reproduced from ref [28].

The swelling-induced ordering of GO layers observed in BGO can be considered as an indication of more homogeneous (compared to HGO) oxidation over the surface of individual flakes and a better defined structure. This suggestion is supported by results of experiments with methanol swelled samples upon temperature variations. Both BGO1 and BGO2 exhibited the same phase transition from the one-layer solvate phase into the two-layer solvate phase below $\sim 245 \mathrm{~K}$, Figure 1. The temperature of transition is nearly identical for these samples despite significant difference in oxidation degree. In contrast, HGO samples exhibit continuous changes of interlayer distance and extremely strong separation of GO layers is achieved at low temperatures [19]. The effect of gradual shift of $\mathrm{d}(001)$ can be explained by interstratification (mixed packing of layers with different thickness) or nonuniform hydration of inter-layers on the nanometer scale (intrastratification) [21, 45]. 
Different interaction of BGO and HGO samples with water is evidenced by the simple observation that HGO can easily be dispersed by sonication to prepare a solution of graphene oxides, while for BGO this procedure does not work. Only using slightly basic solutions (e.g. $0.01 \mathrm{M} \mathrm{NaOH}) \mathrm{BGO}$ can be dissolved to prepare stable single-layered dispersions without sonication.

Further information about the composition of BGO can be extracted from the analysis of TGA/DSC data, Figure 2.

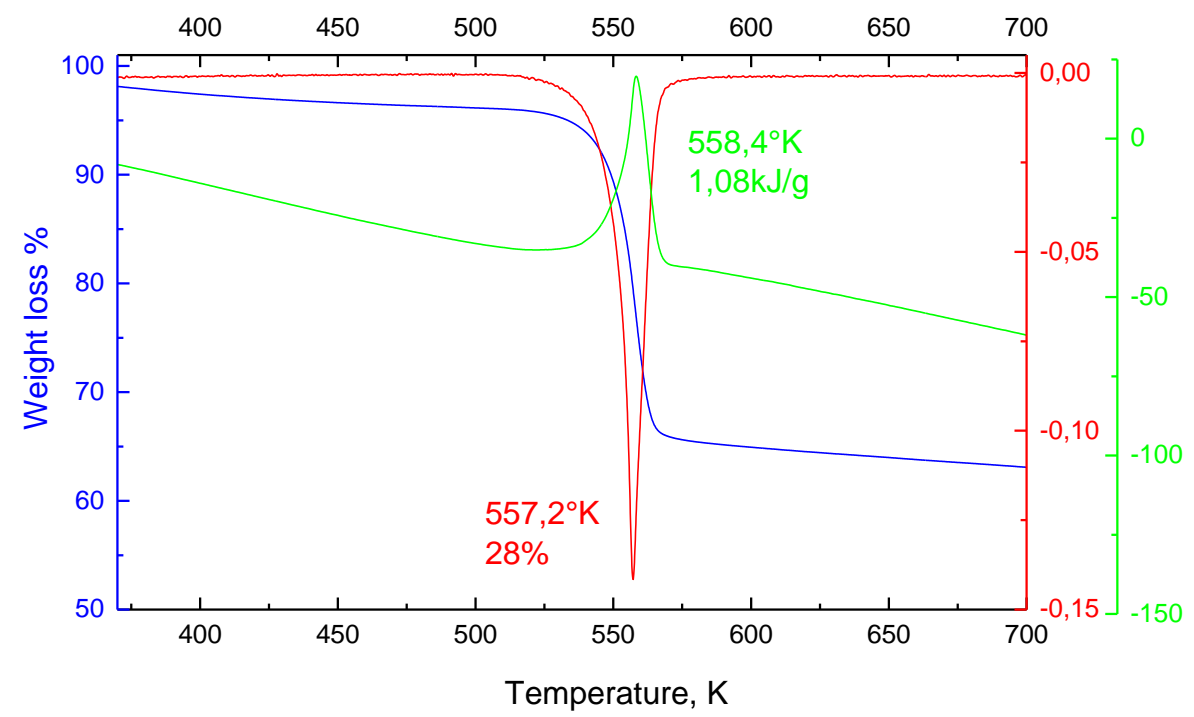

a)

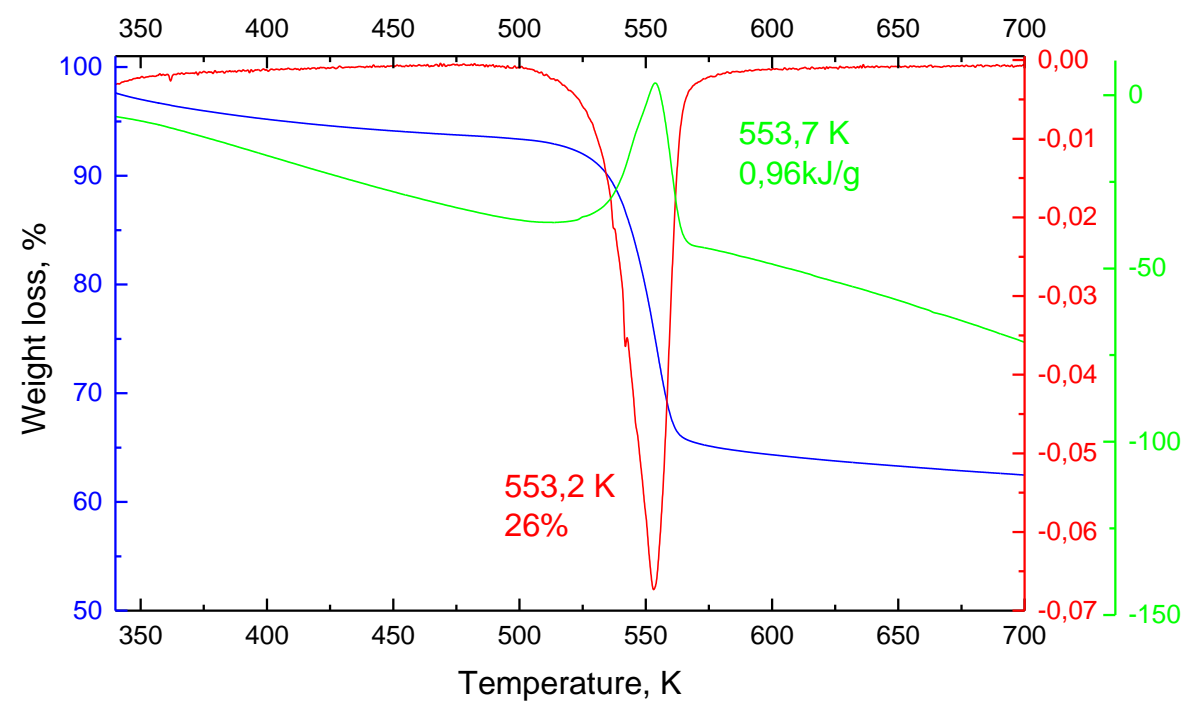

b) 
Figure 2. TGA (blue for weight loss and red derivative of weight loss) DSC (green) traces for BGO2 (a) and BGO1 (b) samples recorded with 5 degrees/min heating rate under nitrogen.

The TGA traces of graphite oxides typically exhibit three regions: the first region below $150^{\circ} \mathrm{C}$ is where water is evaporated, the second region is sharp weight loss between $200^{\circ} \mathrm{C}$ and $300^{\circ} \mathrm{C}$ where explosive thermal degradation of GO occurs and the third, almost flat region is found at higher temperatures. To distinct the major step in thermal degradation of GO from continuous thermal reduction which occur over the broader temperature interval, this step will be named in following discussions as "exfoliation". Comparing TGA traces of BGO1 and BGO2 samples shows a rather unexpected absence of strong difference, neither in exfoliation temperature $\left(280.2{ }^{\circ} \mathrm{C}\right.$ and $284.2{ }^{\circ} \mathrm{C}$, respectively) nor in weight loss $(26 \%$ and $28 \%$, respectively), of the main exfoliation step. However, samples of HGO studied in our TGA experiments always showed lower temperatures for exfoliation $\left(213-220^{\circ} \mathrm{C}\right)$ [27, 46] and a broader interval of temperatures for this step, which is most obvious when plotted in differential curves (about 2-3 times broader peaks compared to HGO samples). HGO samples also demonstrate much higher water loss at temperatures below exfoliation. Both BGO samples exhibited about $5 \mathrm{wt} \%$ loss due to water evaporation, compared to $15-20 \%$ for HGO. Thus, HGO has the ability to sorb more water at the same (ambient) humidity levels.

The very small difference between weight loss of BGO1 and $\mathrm{BGO} 2$ on the exfoliation step, only 2\%), deserves special attention as it visibly contradicts XPS data. Considering the elemental composition of the samples, the expected weight loss, which corresponds to complete removal of all oxygen, should be $23 \%$ and $27 \%$ for BGO1 and $\mathrm{BGO} 2$ respectively. However, the analysis of TGA data is not straightforward due to two reasons: first, it is known that not all oxygen is released from the GO samples and, second, that the gases released on exfoliation steps include $\mathrm{CO}$ and $\mathrm{CO}_{2}$, not oxygen. The formation of holes in the graphene sheets as a result of GO exfoliation is known from the 60-s [33] and was confirmed more recently by direct high resolution microscopy methods [47, 48]. The experimental data shown in Figure 2 indicate that the BGO2 sample releases more carbon (as carbon oxides) compared to BGO1 upon exfoliation. This explanation is logical since more oxidized samples are expected to be more defective and more likely to lose a higher number of carbon atoms reacted with released oxygen-containing groups.

On the other hand, the broader peak observed for the exfoliation of HGO samples should be considered as an evidence of less homogeneous oxidation relative to the BGO oxidation, with some regions of GO sheets more stable and some regions less stable to heating. 
Approximately the same weight loss (25-27\%) for samples with $\mathrm{C} / \mathrm{O}$ of about 2.7 indicates that HGO has more defective graphene skeleton and a higher number of carbon atoms is lost in the exfoliation process. Generally, a lower exfoliation temperature of HGO is evidence for a different type of oxidation rather than a consequence of a different oxidation degree. Note that stronger oxidation results in a slight increase of exfoliation temperature for BGO samples, while for stronger oxidized HGO samples the exfoliation point is about sixty degrees lower.

It should be concluded that the exfoliation temperature is very strongly affected by the type of oxidation rather than the degree of oxidation ( $\mathrm{C} / \mathrm{O}$ ratio). Therefore, it is extremely important to study the difference between BGO and HGO by methods that allow analysis of different functional groups attached to the GO sheets and to make at least relative quantitative estimation of their numbers.

\subsection{Functionality of Brodie and Hummers GO by FTIR and NMR}

Interpretation of spectral data with detailed analysis of functional groups of GO is not unambiguous for the methods used here: XPS, FTIR, NMR and NEXAFS spectroscopy. Rather different assignments are given to the same spectral features in the available literature e.g. for XPS [49, 50] and NEXAFS [42, 51]. Therefore, it is important to verify the interpretations provided by one method with data collected using other methods.

One of the best methods to characterize functional groups of GO is FTIR. The data published in our earlier studies indicate higher relative amounts of $\mathrm{C}=\mathrm{O}$ groups in $\mathrm{HGO}$ and an increased number of $\mathrm{C}-\mathrm{OH}$ groups in BGO [27]. Figure 3 shows FTIR spectra recorded from the BGO1 and BGO2 samples studied here, as well as HGO1. These spectra are in good agreement with the data published for progressively oxidized BGO by Szabo et al [34]. The assignment of FTIR peaks provided in this study will be used in the following discussions. 


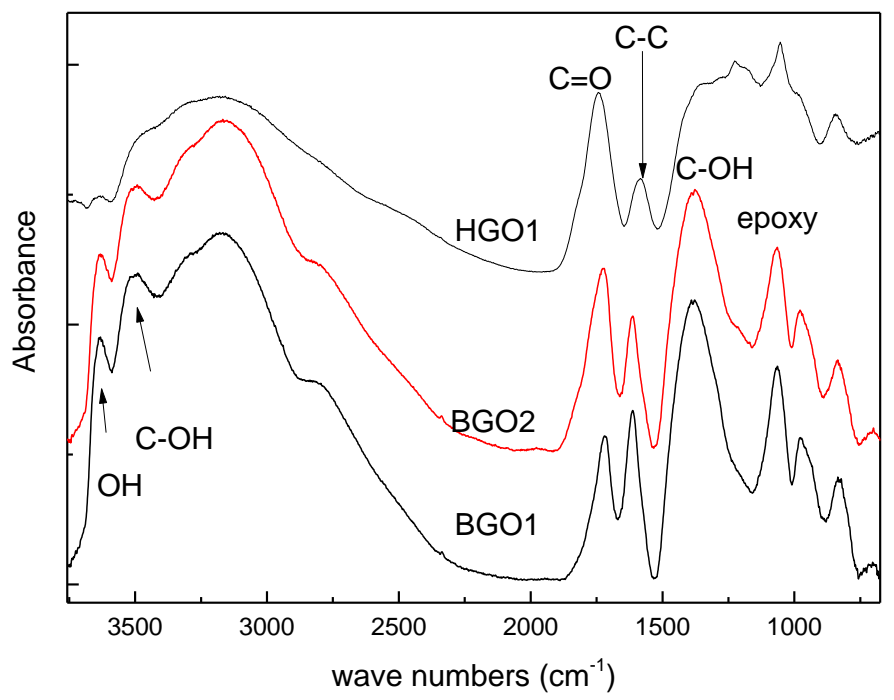

Figure 3. FTIR spectra recorded from powder samples of BGO1, BGO2, and HGO1.

The difference between $\mathrm{BGO} 1$ and $\mathrm{BGO} 2$ samples is most obvious in the spectral region $1500-2000 \mathrm{~cm}^{-1}$ where peaks from aromatic $\mathrm{C}=\mathrm{C}\left(1613 \mathrm{~cm}^{-1}\right)$ and $\mathrm{C}=\mathrm{O}\left(1721 \mathrm{~cm}^{-1}\right)$ vibrations are found. The relative changes in intensity of these peaks should be assigned to the different degrees of oxidation of BGO1 and BGO2 samples. However, the higher in intensity of the peak at $1750 \mathrm{~cm}^{-1}$ for the HGO sample only partly depends on the slightly higher degree of oxidation and can be explained if the relative abundance of $\mathrm{C}=\mathrm{O}$ is higher.

In general, the better resolved and sharper peaks in the spectra of the BGO samples confirm a better defined structure compared to the HGO samples. The vibrational signatures from $\mathrm{OH}$ groups are also more intense and much better resolved in BGO samples. The difference in oxidation degree between BGO1 and BGO2 is evident only in the change of the relative intensity of some peaks while HGO material is clearly different, especially in the spectral region below $1500 \mathrm{~cm}^{-1}$. One need also to take into account that the FTIR spectra were recorded using powders exposed to ambient humidity. According to the TGA data, the HGO samples contains about 2-3 times more moisture compared to BGO samples, which could affect the spectra. The traditional interpretation of FTIR spectra does not provide vibrational signatures that could be confidently assigned to epoxy group oxygen (C-O-C), which is known to be one of the most abundant functional groups in graphite oxides.

Further insight into the details of GO functionalization can be obtained using NMR methods. 


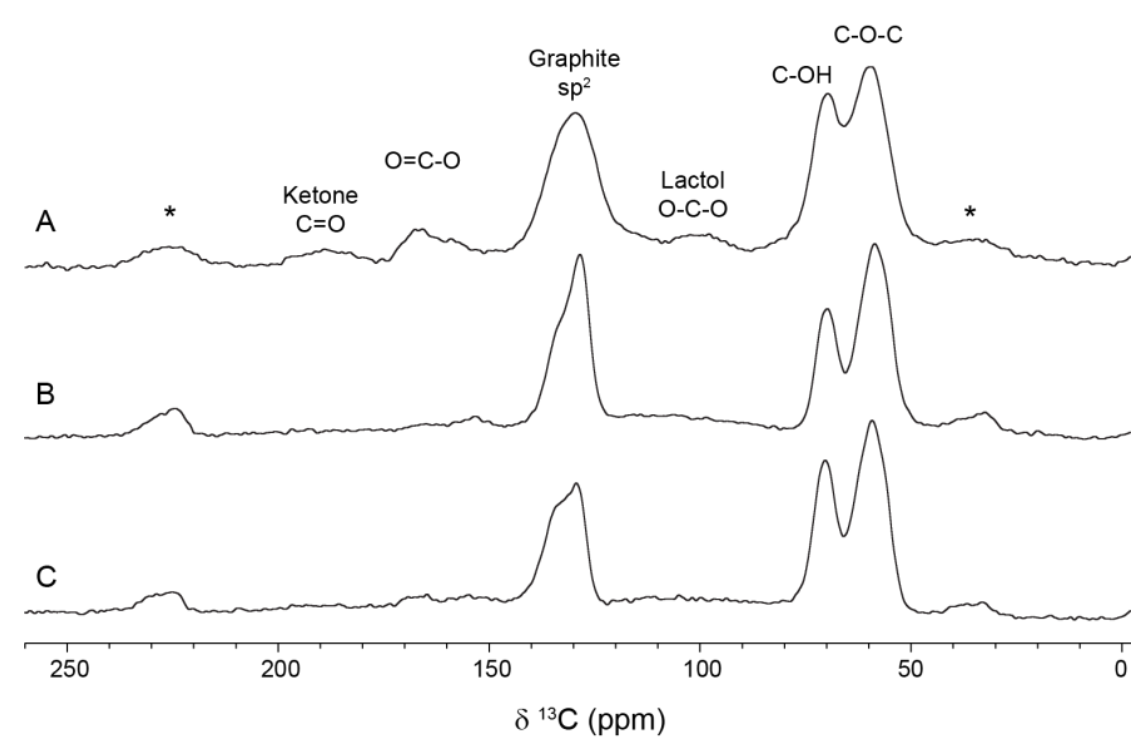

Figure 4. NMR spectra of powder samples of A) $\mathrm{HGO} 2, \mathrm{~B}) \mathrm{BGO} 1$ and C) BGO2

The NMR spectra shown in Figure 4 for the BGO1 and BGO2 samples and for HGO2 provide the assignment for the peaks of the most important functional groups of GO. The major peaks are from epoxy, hydroxyls, and the $\mathrm{C}=\mathrm{C}$ graphene skeleton. Smaller features are assigned also to carboxyl, lactol, and $\mathrm{C}=\mathrm{O}$. Assignments are based on refs $[52,53]$.

Spectra of BGO and HGO2 shown in Figure 4 were recorded with a spin rate of $12 \mathrm{kHz}$ but spectra of BGO was also recorded at $5 \mathrm{kHz}$ in order to compare our results to an earlier study by Szabo et al. [34] Comparing spectra from the different spin rates revealed that many of the previously interpreted signals in the $5 \mathrm{kHz}$ spectrum arise from spinning sidebands. Therefore, the $12 \mathrm{kHz}$ spectra were used for interpretation.

Comparing spectra of BGO and HGO clearly shows that these materials are markedly different. Surprisingly, the BGO samples show a smaller amount of $\mathrm{sp}^{2}$ carbons compared to the HGO sample. This visible paradox can be explained assuming more inhomogeneous oxidation of graphene oxide sheets in HGO. Clustering of functional groups, with the formation of nanometer sized oxidized and not oxidized graphene areas was, indeed, reported earlier by direct HRTEM observations [47]. Existence of large graphene islands was postulated in some studies as typical for "graphite oxide". However, HRTEM studies available in the literature are so far limited only to various types of HGO [47, 48, 54]. Larger relative amounts of epoxy groups may contribute to this effect. Epoxy oxygens connect two carbon atoms while hydroxyl groups are attached to only one carbon. Therefore, with the 
same $\mathrm{C} / \mathrm{O}$ ratio the functionalization with epoxy groups will result in a higher number of carbon atoms affected by oxidation.

This interpretation of NMR data is in good agreement with structural data obtained by $\mathrm{XRD}$, which clearly shows that BGO exhibits better packing of layers and more crystalline structure with well-defined mono-layer steps in intercalation of various polar solvents (e.g. alcohols, acetone, DMF etc). The presence of larger graphene areas in HGO will clearly disrupt the ordering in packing of graphene oxide layers and lead to strongly inhomogeneous hydration/solvation in stronger and weaker oxidized regions. The inhomogeneous hydration of HGO on the nanometer size scale was actually directly observed in earlier published high resolution Scanning Force Microscopy (SFM) studies [45].

\subsection{BGO and HGO powders and thin films by NEXAFS}

NEXAFS spectroscopy is a valuable method to characterize graphene and GO. The fine structure in spectra at the $\mathrm{C} 1 \mathrm{~s}$ edge and the O1s edge exhibits very distinct features. Several earlier published studies reported detailed analysis of GO samples precipitated as thin films or paper-like foils using sonicated dispersions of $\mathrm{HGO}[42,51,55]$. However, the interpretations of these spectra are remarkably different and the identification of spectral signatures for various functional groups is therefore somewhat uncertain. It is also unclear how the conditions of sonication and precipitation affect the structure and chemical composition of thin films.

The difference between $\mathrm{BGO} 2$ and $\mathrm{HGO} 2$ powder samples is obvious from the spectra shown in Figure 5 . In the $\mathrm{C} 1 \mathrm{~s}$ NEXAFS spectrum, HGO2 demonstrates a stronger $\mathrm{C} 1 \mathrm{~s}-\pi^{*}$ resonance at $284.5 \mathrm{eV}$ (peak 1 in Figure 5a), compared to $\mathrm{BGO}$, characteristic for the conjugated $\mathrm{C}=\mathrm{C}$ network of graphene, carbon nanotubes and fullerenes. This corresponds with the NMR results, where a stronger $\mathrm{sp}^{2}$ contribution was found for $\mathrm{HGO} 2$, and would confirm the presence of graphene regions. This difference persists also after dispersion of the precursor GO powders and their re-stacking into thin films, see Figure 6a.

The relative intensity of peaks is somewhat different for the spectra of $\mathrm{C} \mathrm{K}$-edge recorded from $\mathrm{BGO} 2$ and $\mathrm{HGO} 2$ films compared to powders but all the main features remain similar. The changes are almost negligible for $\mathrm{HGO} 2$ samples but for $\mathrm{BGO} 2$ the difference between the precursor GO and thin films is more pronounced. 
Additional information, which may assist to the assignment of peaks, can be obtained from angle-resolved NEXAFS experiments, which allows the detection of the difference in orientation of functional groups relative to the substrate. The angle resolved C1s-NEXAFS spectra of HGO and BGO thin films, prepared by drop casting on Si substrate (Figure 7) show that the $\pi^{*}$ resonance of the unoxidized rings $(\mathrm{C}=\mathrm{C})$ at $284.5 \mathrm{eV}$ shows a very strong dichroism, and increase in intensity with decreasing angle of incoming x-rays. This indeed proves that the $\mathrm{C}=\mathrm{C}$ of the graphene regions are planar and parallel to the surface. $\left(\mathrm{p}_{\mathrm{z}}\right.$ orbital is perpendicular to sample surface).
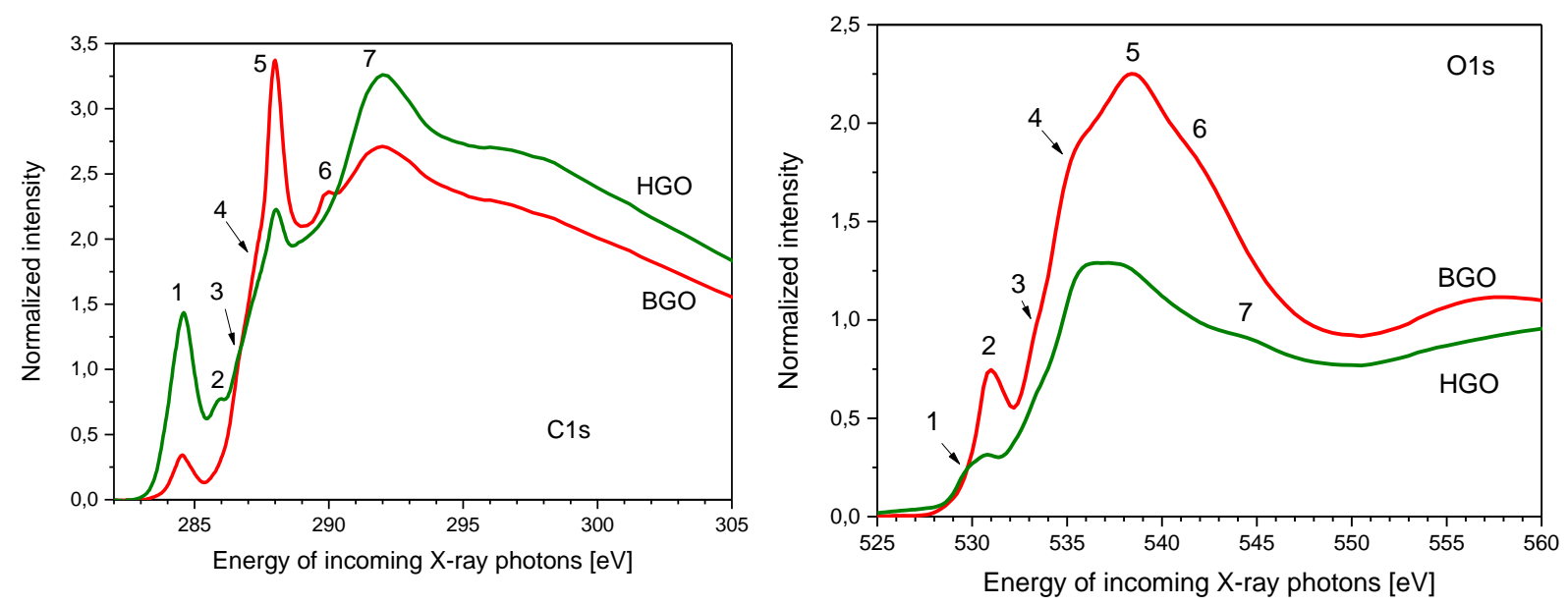

Figure 5. NEXAFS spectra of $\mathrm{BGO} 2$ and $\mathrm{HGO} 2$ powders: a) $\mathrm{C} 1 \mathrm{~s}$ edge, b) O1s edge. Assignment of peaks is given in Tables 1 and 2.
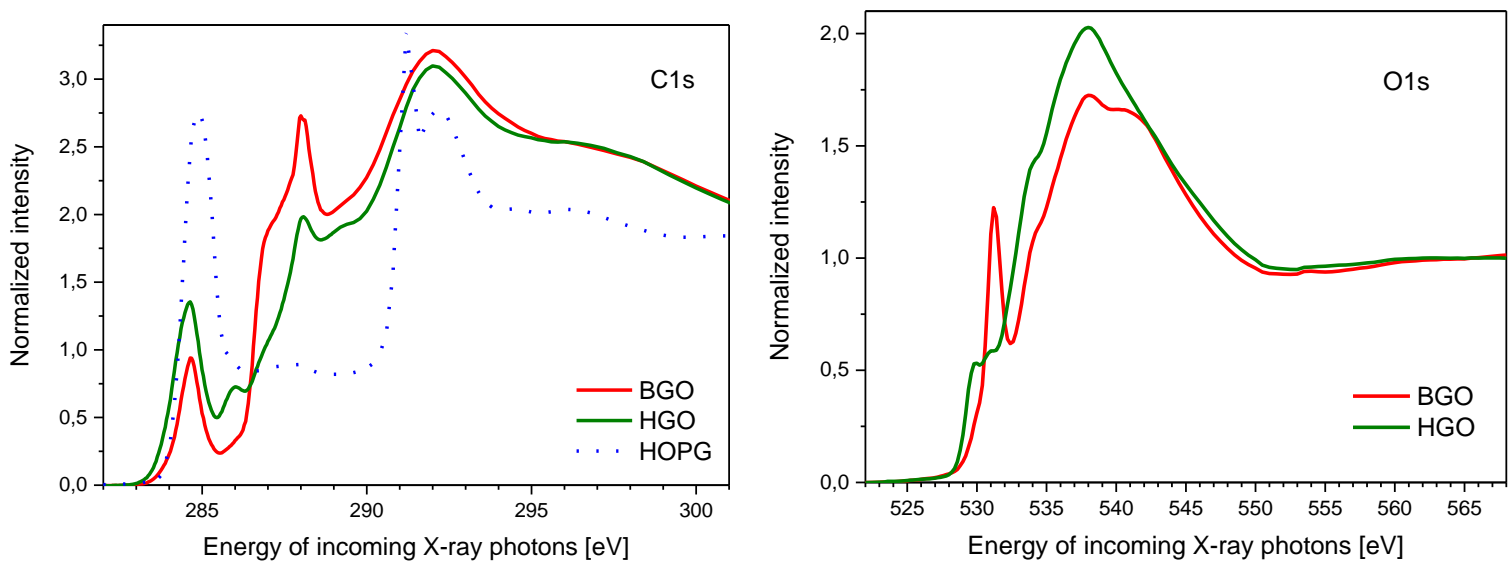

Figure 6. NEXAFS spectra of $\mathrm{BGO} 2$ and $\mathrm{HGO} 2$ thin films: a) $\mathrm{C} 1$ s edge, b) O1s edge. See Tables 1 and 2 for detailed assignment. 
The other dominant peak in the C1s NEXAFS spectra (Fig 5a and Fig 6a) is the resonance at $288.0 \mathrm{eV}$ (peak 5 in Figure 5a). This peak is much stronger in BGO powder samples than in HGO powder. In the literature, this peak is usually assigned to $\mathrm{C}=\mathrm{O}$ from carbonyl or carboxylic acid groups $[42,51,55]$ (See Table 1). This is in contradiction to the NMR and FTIR results presented above, and earlier results that have shown higher relative amounts of $\mathrm{C}=\mathrm{O}$ groups in $\mathrm{HGO}$ than in $\mathrm{BGO}$ [27]. This peak demonstrates only a weak dichroism (Figure 7), as does the peak at $292 \mathrm{eV}$, which indicates that the orbital responsible for this resonance is oriented randomly rather than in-plane or face-on.
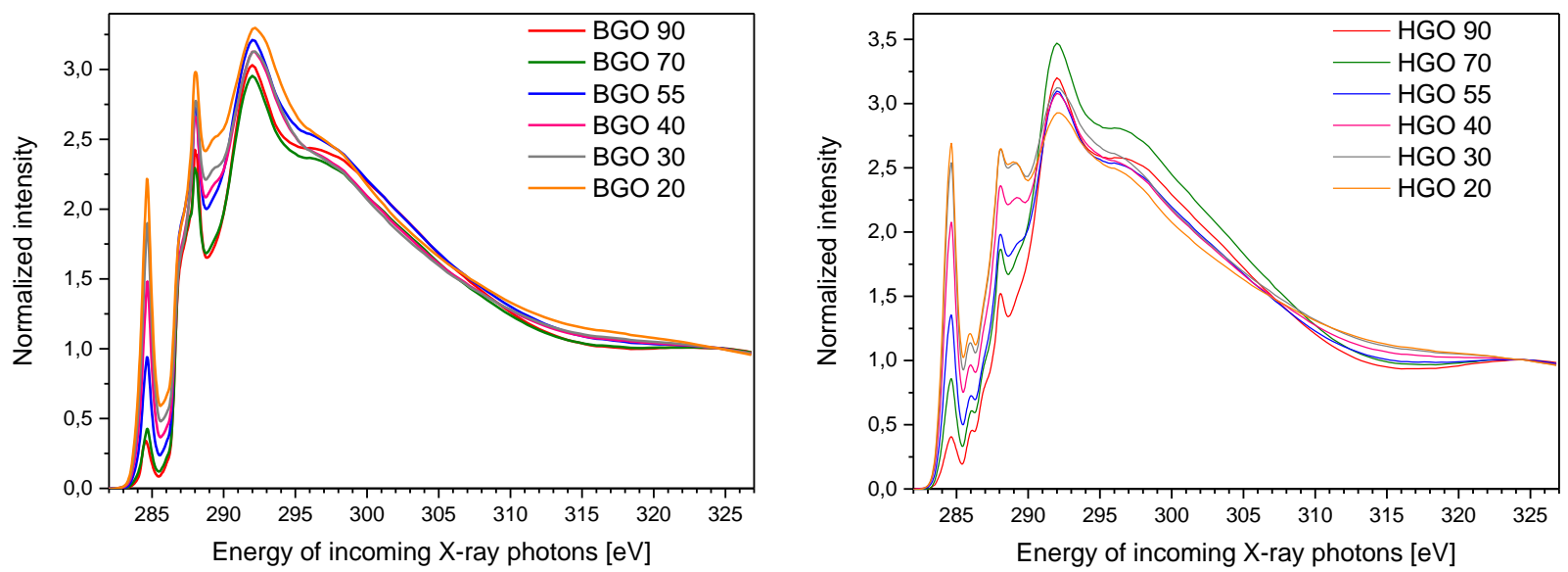

Figure 7. Angular dependence of $\mathrm{C} 1 \mathrm{~s}$ NEXAFS spectra for $\mathrm{BGO} 2$ and $\mathrm{HGO} 2$ films.

Graphite oxides are known to be functionalized with hydroxyl and epoxy groups on the planar surface while the edges are terminated by carboxyl or carbonyl. Considering that flake size is on micrometer level the edge functional groups must be present only in rather minor proportion. It would therefore be surprising if the peak at $288.0 \mathrm{eV}$, being one of the strongest in the NEXAFS spectra, originates from carbonyl and carboxyl groups, which can only be placed on the edges of GO flakes or edges of holes in these flakes. Also, considering that the intensity of $288.0 \mathrm{eV}$ peak is higher in $\mathrm{BGO}$, it would be more reasonable if this peak were due to hydroxyl groups found to be more abundant in this sample, in agreement with NMR and FTIR.

However, also the O1s NEXAFS spectrum confirms a larger presence of $\mathrm{C}=\mathrm{O}$ in the $\mathrm{BGO}$ samples than in the HGO, because the resonance at $530.9-531.2 \mathrm{eV}$ in the O1s NEXAFS spectra (Figure 5b and Figure $\mathbf{6 b}$ ) is indeed more dominant in BGO than in HGO samples. Showing up at low photon energies, this resonance must be of $\pi^{*}$ nature, i.e. double bonded oxygen (see discussion of O1s NEXAFS spectra below). 
The only assignment that can explain both the $\mathrm{C} 1 \mathrm{~s}$ and the $\mathrm{O} 1 \mathrm{~s}$ spectral features is the $\mathrm{C}=\mathrm{O}$, and hence we have to draw the conclusion that the BGO sample surfaces studied in NEXAFS contained more carbonyl and carboxyl groups than the HGO sample surfaces. The assignments of all peaks in the C1s NEXAFS spectrum, based on literature data, is provided in Table 1.

\begin{tabular}{|c|c|c|c|c|c|c|c|c|}
\hline $\mathrm{N}$ & $\begin{array}{l}\mathrm{BGO} 2 \\
\text { powder }\end{array}$ & $\begin{array}{l}\text { BGO2 } \\
\text { films }\end{array}$ & $\begin{array}{l}\mathrm{HGO2} \\
\text { powder }\end{array}$ & $\begin{array}{l}\text { HGO2 } \\
\text { films }\end{array}$ & $\begin{array}{l}\text { HGO paper } \\
\text { (Hunt et al, } \\
2012[40] \text { ) }\end{array}$ & $\begin{array}{l}\text { HGO films } \\
\text { (Lee, } 2012 \\
{[49] \text { ) }}\end{array}$ & \begin{tabular}{|l} 
HGO films \\
(Ganguly, \\
2011 [47])
\end{tabular} & $\begin{array}{l}\text { Orientation } \\
\text { (from angular } \\
\text { resolved NEXAFS } \\
\text { spectra) }\end{array}$ \\
\hline 1 & 284.5 & 284.7 & 284.6 & 284.6 & $\begin{array}{l}285.0 \\
\mathrm{C}=\mathrm{C} \pi^{*}\end{array}$ & & $\begin{array}{l}285.2 \\
\mathrm{C}=\mathrm{C} \pi^{*}\end{array}$ & $\begin{array}{l}\text { in plane }\left(\mathrm{p}_{\mathrm{z}} \text { orbitals }\right. \\
\text { perpendicular to } \\
\text { plane })\end{array}$ \\
\hline 2 & & & 285.9 & 285.9 & & & & $\begin{array}{l}\text { Slight preferential } \\
\text { orientation in plane }\end{array}$ \\
\hline 3 & $(286.7)$ & 286.8 & & & $\begin{array}{l}286.0-286.4 \\
\text { C-OH }\end{array}$ & $\begin{array}{l}286.7 \\
\mathrm{C}-\mathrm{O} \pi^{*} \text { in } \\
\mathrm{C}-\mathrm{OH}\end{array}$ & & \\
\hline 4 & $(287.2)$ & 287.4 & $\begin{array}{l}(287.2) \\
\end{array}$ & 287.0 & $\begin{array}{l}287.2-288.3 \\
\text { epoxy } \\
\text { C-O-C }\end{array}$ & $\begin{array}{l}287.5 \\
\mathrm{C}-\mathrm{O} \pi \text { in } \\
\mathrm{C}-\mathrm{O}-\mathrm{C}\end{array}$ & \begin{tabular}{|l|}
287 \\
C-OH \\
C-O-C
\end{tabular} & \\
\hline 5 & 288.0 & 288.1 & 288.0 & 288.1 & $\begin{array}{l}287.5-288.1 \\
\mathrm{C}=\mathrm{O}\end{array}$ & $\begin{array}{l}288.7 \\
\mathrm{C}=\mathrm{O} \pi^{*} \text { in } \\
\mathrm{CO}\end{array}$ & \begin{tabular}{|l|}
288.7 \\
$\mathrm{C}=\mathrm{O}$ \\
$\mathrm{COOH}$
\end{tabular} & \\
\hline 6 & 289.8 & & & 289.2 & \begin{tabular}{|l}
288.5 \\
$\mathrm{COOH}$
\end{tabular} & $\begin{array}{l}289.8 \\
\mathrm{C}=\mathrm{O} \pi^{*} \text { in } \\
\mathrm{COOH}\end{array}$ & $\mathrm{COOH}$ & \\
\hline 7 & 292.2 & 292.0 & 292.0 & 292.0 & $\mathrm{C}=\mathrm{C} \sigma^{*}$ & $\begin{array}{l}293.0 \\
\mathrm{C}=\mathrm{C} \sigma^{*}\end{array}$ & & $\begin{array}{l}\text { First sigma } \\
\text { resonance (Picalé) }\end{array}$ \\
\hline
\end{tabular}

Table 1. Experimentally observed peak positions for $\mathrm{C} 1 \mathrm{~s}$ NEXAFS. The most intensive absorptions are marked in bold. Tentative assignment of peak and literature data according to refs. $[42,51,55]$

The C1s-NEXAFS spectrum of BGO films shows an increase in the resonance at $287.2 \mathrm{eV}$ (peak 4 in Fig 6a) for thin films, compared to BGO powder. This peak is assigned to carbon in epoxy and ether groups. It is almost absent in HGO samples. This correlates well with the observation from FTIR that the BGO films have more abundant epoxy groups than HGO. Also the O1s NEXAFS spectra show intensive resonances associated with oxygen in epoxy and hydroxyl groups (peaks 4 and 5 in Fig 5b).

We note a small peak at $285.9 \mathrm{eV}$ present in the $\mathrm{C} 1 \mathrm{~s}$ spectra of the $\mathrm{HGO}$ samples (peak 2 in Figures 5a and 6a) which is unassigned in the literature. This peak is almost absent in BGO 
samples. The intensity of this peak increases with decreasing incident angle indicating that the orbital responsible for the final state of this transition is oriented preferentially perpendicular to the surface plane. If this is a $\pi^{*}$ orbital this corresponds with double bonds ( $\mathrm{C}=\mathrm{O}$ for instance) in plane with the surface, while if this is a $\sigma^{*}$ orbital this indicates oriented $\sigma$-bonds perpendicular to the surface.

Similarly, the low intensity of the peak at $289.8 \mathrm{eV}$ in the C1s-NEXAFS spectra of HGO films and for BGO powder samples, and to a smaller extend in BGO films, (Figure 6a) also shows a weak dichroism. This indicates either a $\pi^{*}$ orbital $(\mathrm{C}=\mathrm{O}$ for instance $)$ oriented in plane or a $\sigma^{*}$ orbital oriented preferentially perpendicular to the surface. We can conclude from comparing the angular resolved C1s NEXAFS spectra that HGO samples show a slightly stronger dichroism relative to BGO and also a larger number of functional groups that are preferentially oriented compared to BGO.

The difference between $\mathrm{BGO}$ and $\mathrm{HGO}$ is even stronger in the spectra recorded for $\mathrm{O} 1 \mathrm{~s}$ NEXAFS (Figure 5b). For the O1s NEXAFS spectra the assignments are presented in Table2. The O1s NEXAFS spectra show also stronger difference between precursor BGO powder and film deposited using this precursor. For example, as mentioned earlier, a rather sharp resonance is observed at 530.9 - $531.2 \mathrm{eV}$ (peak 2 in Figure 5b), with increased intensity in thin film spectra of BGO. This peak is a $\pi^{*}$ resonance, originating from transitions of $\mathrm{C} 1 \mathrm{~s}$ core level to $\pi^{*} \mathrm{C}=\mathrm{O}$ in carboxylic acid and/or ketones. This is accompanied by an increased absorption and appearance of a shoulder at $542 \mathrm{eV}$ (peak 6 in Figure 5b) in BGO samples, which is assigned to $\sigma^{*}(\mathrm{C}=\mathrm{O})$ by Lee et al.[55] There is no counterpart to this peak in HGO samples. Once again, the relative numbers of carbonyls and carboxyl should expected to be small in BGO samples, but the observation of major NEXAFS resonances and their assignment to these functional groups (as in refs $[51,54,55]$ ) seems to be confronting previous knowledge about GO. More detailed theoretical and experimental studies are required to verify the assignment of NEXAFS peaks which is out of the scope of this study.

\begin{tabular}{|l|l|l|l|l|l|l|l|}
\hline $\mathrm{N}$ & $\begin{array}{l}\text { BGO } \\
\text { powder }\end{array}$ & $\begin{array}{l}\text { BGO } \\
\text { film }\end{array}$ & $\begin{array}{l}\text { HGO } \\
\text { powder }\end{array}$ & $\begin{array}{l}\text { HGO } \\
\text { film }\end{array}$ & $\begin{array}{l}\text { HGO film } \\
\text { (Pacilé, 2011 [48]) }\end{array}$ & $\begin{array}{l}\text { HGO films } \\
\text { (Ganguly, } \\
\text { 2011 [47]) }\end{array}$ & $\begin{array}{l}\text { HGO films } \\
\text { (Lee, 2012 } \\
[49])\end{array}$ \\
\hline 1 & & & 529.8 & 529.7 & & COOH & \\
\hline $\mathbf{2}$ & $\mathbf{5 3 0 . 9}$ & $\mathbf{5 3 1 . 2}$ & 530.4 & 530.4 & $531.5 \pi^{*}(\mathrm{C}=\mathrm{O})$ & COOH & $\begin{array}{l}531.5 \\
\text { COOH }\end{array}$ \\
\hline 3 & 533.5 & 533.8 & 533.4 & 533.6 & $534.0 \pi^{*}(\mathrm{C}-\mathrm{O})$ & $\mathrm{C}=\mathrm{O}$ & \\
\hline
\end{tabular}




\begin{tabular}{|c|c|c|c|c|c|c|c|}
\hline & & & & & & $\mathrm{C}-\mathrm{O}-\mathrm{C}$ & \\
\hline 4 & 535.5 & 536.0 & 535.8 & 536.0 & $535.5 \sigma^{*}(\mathrm{O}-\mathrm{H})$ & $\begin{array}{l}\mathrm{C}-\mathrm{OH}, \\
\mathrm{COOH}\end{array}$ & \\
\hline & & 537.7 & & & & $\begin{array}{l}\mathrm{C}-\mathrm{OH}, \\
\mathrm{COOH}\end{array}$ & \\
\hline 5 & $\begin{array}{l}538.3 \\
\end{array}$ & & 538.6 & 538.4 & $540.0 \sigma^{*}(\mathrm{C}-\mathrm{O})$ & $\begin{array}{l}\mathrm{C}-\mathrm{OH}, \\
\mathrm{COOH}\end{array}$ & $\begin{array}{l}\mathrm{C}-\mathrm{OH} \\
\mathrm{C}-\mathrm{O} \\
\mathrm{C}=\mathrm{O}\end{array}$ \\
\hline 6 & 541.9 & 541.6 & & & $542.0 \sigma^{*}(\mathrm{C}=\mathrm{O})$ & $\begin{array}{l}\mathrm{C}=\mathrm{O}, \\
\mathrm{C}-\mathrm{O}-\mathrm{C}\end{array}$ & \\
\hline 7 & & & 543.3 & & $544.5 \sigma^{*}(\mathrm{C}=\mathrm{O})$ & $\begin{array}{l}\mathrm{C}=\mathrm{O}, \\
\mathrm{C}-\mathrm{O}-\mathrm{C}\end{array}$ & \\
\hline
\end{tabular}

Table 2. Experimentally observed peak positions for O1s edge tentative assignment of peak and literature data according to refs. $[42,51,54,55]$

Summarizing this part, strong orientation of the graphene $\mathrm{C}=\mathrm{C}$ bonds, planar to the surface was observed by angle-resolved experiments. Furthermore, relatively weak orientation effects were observed for functional groups related to carbonyl and carboxyl. The GO membranes shrink very strongly in the process of drying and form wave like formations, which result in orientation of individual flakes, which significantly deviates from parallel to the substrate. If the edges of flakes (outer edges and edges of holes) are slightly bend or wrapped, this would further reduce orientation effects. The geometry of thin films prepared by drop casting and drying on Si plates must resemble the shape of $\mu$ m-thick GO membranes discussed below (Figure 8).

\subsection{Mechanical properties of BGO and HGO membranes/papers}

Mechanical properties of membranes prepared using the $\mathrm{BGO} 2$ precursor were compared with membranes prepared using two Hummers precursors (HGO2 and HGO3). Similar deposition conditions were used for preparation of these membranes. As expected the membranes consist of densely packed GO flakes approximately parallel to each other but with wave like shape acquired as a result of post-preparation drying, Figure 8. 

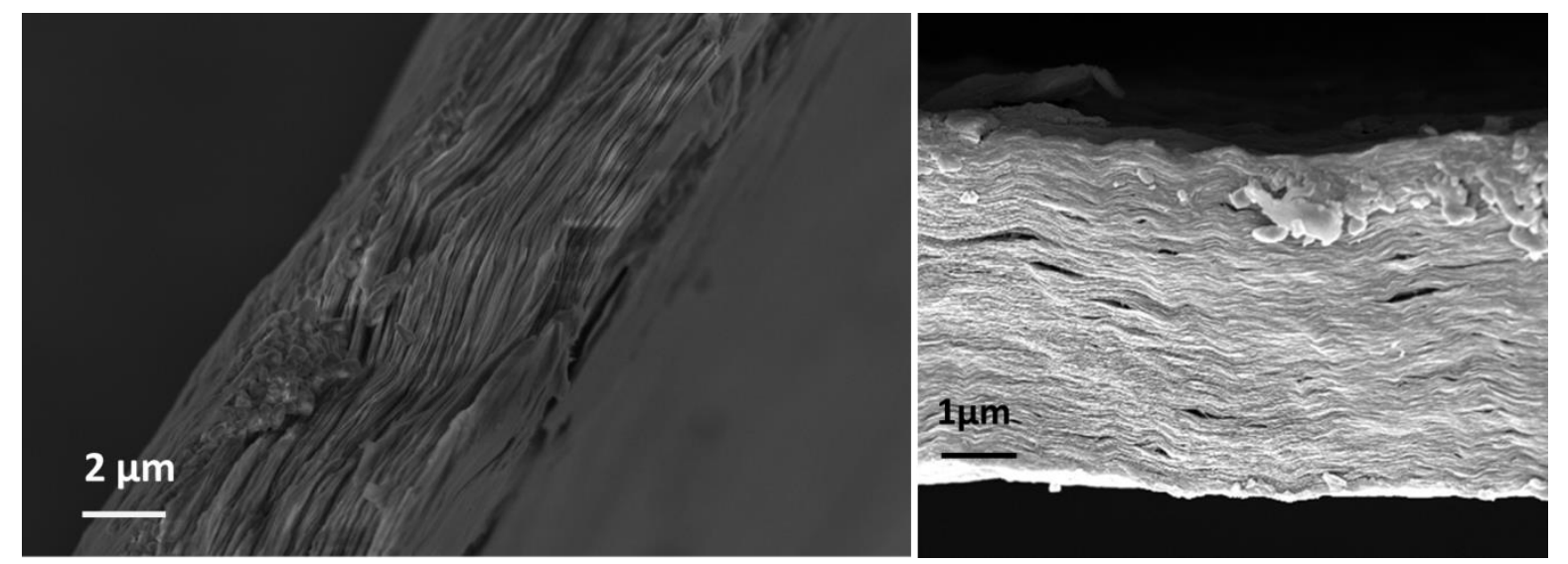

Figure 8. SEM images of edge regions recorded from $\mathrm{HGO} 1$ and $\mathrm{BGO} 2$ membranes after mechanical tests.

In general, $\mathrm{BGO} 2$ membranes are more transparent for samples with comparable thickness and less fragile when operated and mounted. In fact, attempts to characterize bending properties demonstrated that all samples survive bending test with minimal bending radius of $4.5 \mathrm{~mm}$. However, the BGO2 samples are clearly more flexible and able to restore the initial shape even after multiple folding cycles whereas HGO3 membranes break into pieces when folded.

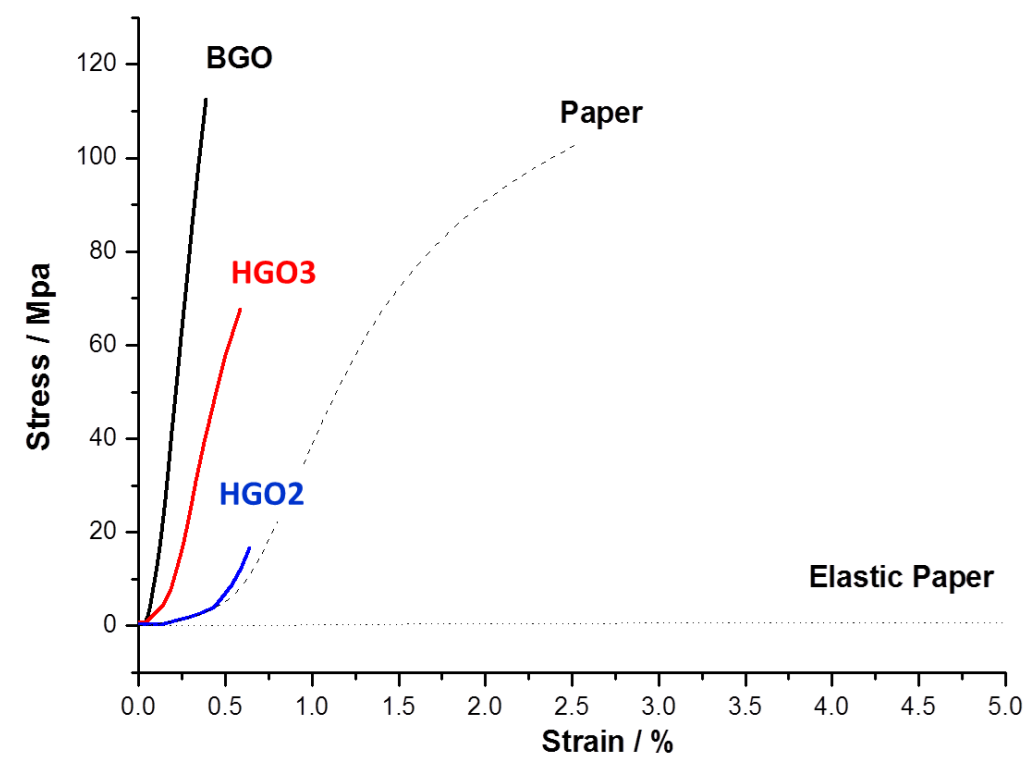

Figure 9. Stress vs strain diagram for three tested samples of GO membranes/papers.

Standard printer paper with $0.03 \mathrm{~mm}$ was used as a reference and “'Fisherbrand" ${ }^{\mathrm{TM}} \mathrm{Lab}$ Wipes" with $0.3 \mathrm{~mm}$ thickness as an example of elastic paper. 


\begin{tabular}{|l|l|}
\hline Sample Strain $\mathbf{0 . 1 - 0 . 2 \%}$ & Young's modulus (MPa) \\
\hline BGO ambient & 24229 \\
\hline BGO vacuum dried $25^{\circ} \mathrm{C} 72 \mathrm{hrs}$ & 20019 \\
\hline BGO $80 \%$ humidity $25^{\circ} \mathrm{C} 72 \mathrm{hrs}$ & 14448 \\
\hline HGO2 ambient & 200.6 \\
\hline HGO2 vacuum dried $25^{\circ} \mathrm{C} 72 \mathrm{hrs}$ & 2684 \\
\hline HGO2 $80 \%$ humidity $25^{\circ} \mathrm{C} 72 \mathrm{hrs}$ & 186.2 \\
\hline
\end{tabular}

Table 3. Young modulus values determined for several GO membranes samples at conditions of varying humidity. The values are average numbers for 3 measurements each.

Measurements of Young's modulus showed that BGO2 membranes are superior to both HGO samples. As it is known that GO swells proportionally to humidity, we also tested our samples in vacuum dried conditions and under $80 \%$ humidity inside of environmental chamber. The humidity was strictly controlled by a Voetch environmental chamber. Surprisingly, vacuum drying had different effects on the mechanical properties of BGO2 and HGO membranes compared to the tests performed at ambient conditions ( 45\% humidity). The Young's modulus decreased by $\sim 17 \%$ as result of vacuum drying for BGO (from 24229 to $20019 \mathrm{Mpa}$ ), but increased by almost 10 times for HGO2 sample (from 200.6 to 2684 Mpa, Table 3). An increase in humidity to $80 \%$ resulted in a degradation of the mechanical strength of both BGO and HGO membranes.

Decline in mechanical strength of GO papers at higher humidity is known phenomena related to swelling of GO structure in water vapors.[6] Increase in inter-layer distance of GO structure as a function of humidity is expected to result in weaker bonding and lower Young's modulus. Therefore, it is important to compare mechanical properties of GO membranes at moisture free conditions. The data shown in the Table 3 demonstrate superior mechanical properties of BGO both at vacuum dried state and under conditions of ambient humidity.

The Young's modulus values found in our experiments are not record high compared to earlier reported results.[6] However, the difference between BGO and HGO is remarkable. 
Understanding the mechanism behind the superior mechanical strength of BGO membranes can be of high value for design of even stronger multilayered materials, which could be useful in a variety of functional applications.

As it follows from our results, the mechanical properties of GO membranes strongly depend on the synthetic method.

In principle, several parameters could be suggested as the reason for the difference in mechanical properties of BGO and HGO observed in our experiments: for example the size of the GO flakes, the degree of oxidation, the precise geometry of the flakes packing in the multilayered structure. However, characterization demonstrates that our BGO and HGO samples are oxidized to a similar extent and with similar flake size. The specific pressure applied in the process of membrane preparation or conditions of membrane drying could also affect the mechanical properties. However, deposition of membranes from graphene oxide solutions was performed using identical vacuum filtration conditions. Therefore, we suggest that the superior mechanical properties of BGO membranes must be explained by intrinsic properties of the Brodie oxidation method and certain structural features of the BGO precursor, such as, e.g., relative numbers or specific distribution of oxygen-containing groups over GO flakes surface.

In order to verify the reasons behind the difference in mechanical strength of BGO and HGO membranes, we performed an additional test of the membranes/papers using XPS (Figure 10).
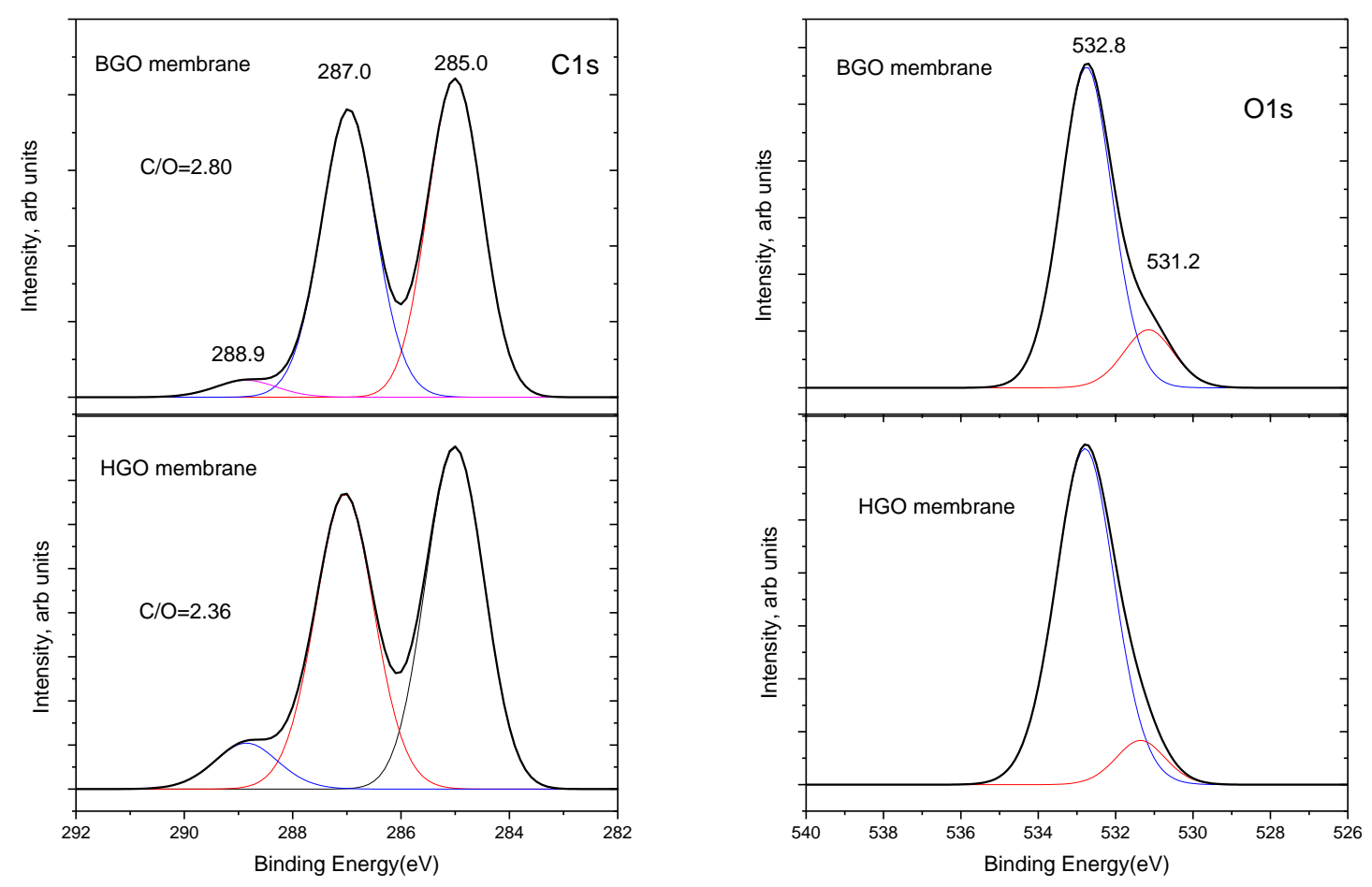
Figure 10. XPS spectra recorded from membrane samples of $\mathrm{BGO} 2$ and $\mathrm{HGO} 2$ in $\mathrm{C} 1 \mathrm{~s}$ and O1s regions.

For both the $\mathrm{HGO} 2$ and $\mathrm{BGO} 2$ samples the $\mathrm{C} / \mathrm{O}$ ratio remained almost the same as in precursor powders but some changes in the relative intensity of the peaks were observed. The spectra of $\mathrm{HGO} 2$ and $\mathrm{BGO} 2$ membranes also look very similar to each other both for $\mathrm{C} 1 \mathrm{~s}$ and O1s peaks. The only significant difference is the about twice higher intensity of the $288.9 \mathrm{eV}$ peak for HGO. This peak is typically assigned to carboxylic groups on the edges of GO flakes. However, considering the micrometer size of the flakes, the number of edge carbon atoms must be negligibly small. Therefore, the relatively strong $\mathrm{COOH}$ peak (about 2.2 at \% for $\mathrm{BGO} 2,5.09$ at\% for $\mathrm{HGO} 1$ and 6.1 at\% for $\mathrm{HGO} 2$ ) should be assigned to the edges of holes in the GO flakes. If this suggestion is true, the relative intensity of the 288.9 $\mathrm{eV}$ peak provides a signature for defects of a given GO material. Higher intensity of this peak in HGO corresponds then to a structure of flakes with more holes. It does not provide, however, information about the size of the holes or exact proportion of their area relative to the whole area of the flake.

Interpretation of XPS spectra presented above is in agreement with better mechanical strength of BGO membranes/papers, which can be suggested to originate from a less defective state of this material. It cannot, however, be ruled out either that the small impurity of $\mathrm{Na}$ observed in our BGO membranes or the absence of sulphur could contribute to difference compared to HGO.

\section{Discussion}

The data presented in this and earlier studies provide evidence for strong differences between the properties of Brodie and Hummers graphite oxides. It is clear that results obtained for one of these materials cannot be directly applied to the other as it is sometimes done in the literature. In the other hand, the difference provides additional opportunities and flexibility for various applications of GO.

The data shown in this paper suggest that the difference between the properties of BGO and HGO can be explained by a stronger disruption of the graphene skeleton in HGO. In agreement with earlier observations, [27, 32] BGO shows a higher relative amount of epoxy 
and hydroxyl groups, which occupy the planar surface of graphene oxide flakes. Several characterization methods independently verify that HGO has more carbonyl and carboxyl functional groups, which introduce defects in the hexagons of graphene $\mathrm{C}=\mathrm{C}$ network: vacancies and holes. Formation of this type of defects is likely to be caused by the potassium permanganate used in the Hummers method. Some earlier studies reported complete absence of carboxyl groups in their samples prepared using the Staudenmaier method: this method also uses chlorate and nitric acid, as in the Brodie method but with addition of sulfuric acid [31]. It has to be noted that interpretation of the NEXAFS spectra, following the assignments given in the literature, is the only method which so far yields an contradicting result: higher abundance of carbonyl and carboxyl groups at the surfaces of HGO relative to BGO. This interpretation of NEXAFS also confronts very recent data which show higher mechanical strength of individual BGO sheets compared to $\mathrm{HGO}$, thus providing evidence of less defective state of BGO [56]. It might be an indication that further theoretical and experimental studies are required for assignment of spectral features in NEXAFS.

The presence of 2-5 at\% of carbon in carboxylic groups in GO can be explained only if a significant number of holes is present on the graphene oxide sheets. Counting only carbon atoms on the edges of micrometer sized flakes would result in negligibly small contribution.

A second important parameter, which is likely to affect the properties of GO, is the distribution of functional groups over the surface of the flakes. Some of the data obtained in our study point to a more homogeneous distribution of oxygen-containing groups over the surface of BGO, while in $\mathrm{HGO}$ some graphene-like areas and stronger clustering of functional groups can be suggested.

Assuming more defects and a more disrupted carbon network in HGO and the existence of "graphene" islands on the surface explain most of the major observations that we presented in this study.

The differences between BGO and HGO can be summarized as following:

- XRD shows better ordering of the layered structure in BGO which further improves when the material is immersed into liquid polar solvents (e.g. alcohols). BGO also shows reversible phase transitions upon temperature or pressure variations due to insertion and de-insertion of solvent layers. These phase transitions are absent in HGO and the temperature shifts of $\mathrm{d}(001)$ are gradual.

Defects and holes are likely to affect the ordering of HGO layers while a inhomogeneous distribution of functional groups will result in stronger swelling of 
more oxidized regions thus providing conditions for effects of inter and intrastratification.

Inhomogeneous hydration of HGO on nanometer size scale is also confirmed by direct SFM observations[45].

- Nearly identical phase transitions occur for BGO with a large difference in oxidation degree $(\mathrm{C} / \mathrm{O}=2.7$ and $\mathrm{C} / \mathrm{O}=3.4)$ which indicates that change in $\mathrm{C} / \mathrm{O}$ ratio itself is unlikely to be major reason for the presence or absence of these transitions in HGO.

- HGO absorbs about 3-4 times larger amount of water at ambient conditions ( 15-20 $\mathrm{wt} \%$ ) compared to BGO as it is evident from TGA traces. A less planar shape of HGO flakes and presence of larger number of holes is expected to provide more space for water sorption. It is also in line with stronger swelling of HGO in water and other polar solvents.

- Thermal exfoliation of BGO occurs at temperatures at least tens of degrees higher compared to HGO and with a steeper step on the weight loss curve. The lower temperature of HGO exfoliation and broader weight loss step are compatible with suggestion of more defects and more inhomogeneous distribution of functional groups.

- Thermal exfoliation of BGO results in higher BET surface areas compared to HGO. This can be assigned to higher temperature of exfoliation, thus the buildup of pressure due to release of gases is stronger between individual GO sheets and stronger explosion is the reason for more defective state of thermally exfoliated GO samples.

- The higher mechanical strength of multilayered membranes prepared from BGO can be considered as an evidence of less defective flakes and a consequence of their more parallel packing evident from XRD. A larger amount of water adsorbed at ambient conditions by $\mathrm{HGO}$ is another factor how defects and disorder could affect mechanical properties adversely.

In summary, we analyzed the difference between BGO and HGO powder samples and in addition multilayered membranes/papers. The pronounced difference is in agreement with the suggested less defective nature of $\mathrm{BGO}$ and a more homogeneous distribution of functional groups over its surface. The smaller amount of carbonyl and carboxyl groups in BGO is suggested by XPS, NMR and FTIR recorded from powder samples, but is not in agreement with NEXAFS data recorded on drop casted thin films. The relatively high percentage of carbonyl and carboxyl groups detected in HGO by XPS must result in the 
presence of a significant number of holes in these GO flakes and a strong disruption of the graphene structure. The less defective BGO flakes arranged into multilayered membranes/papers exhibited superior mechanical properties compared to HGO.

\section{Acknowledgements}

The authors acknowledge the facilities and technical assistance of Cheng C. N. at the Umea Core Facility Electron Microscopy (UCEM) at the Chemical Biological Centre (KBC) and Vibrational Spectroscopy Platform Umeå University. We are grateful to the staff at beamline D1011 of the National Laboratory for Synchrotron Radiation in Lund, Sweden, for technical support. A.T. acknowledges financial support from Carl Tryggers Stiftelse and from the Graphene Flagship (contract no. NECT-ICT-604391). D.W. would like to acknowledge the funding from the European Union Seventh Framework Programme under grant agreement no. 604391 Graphene Flagship. EM acknowledges financial support from the Göran Gustafsson Foundation for Research in Natural Sciences and Medicine and from the Swedish Research Council.

\section{References}

[1] H.P. Boehm, A. Clauss, U. Hofmann, Graphite Oxide and Its Membrane Properties, J Chim Phys Pcb 58(1) (1961) 141-147.

[2] N.A. Kotov, I. Dekany, J.H. Fendler, Ultrathin graphite oxide-polyelectrolyte composites prepared by self-assembly: Transition between conductive and non-conductive states, Adv Mater 8(8) (1996) 637-641.

[3] N.I. Kovtyukhova, P.J. Ollivier, B.R. Martin, T.E. Mallouk, S.A. Chizhik, E.V. Buzaneva, A.D. Gorchinskiy, Layer-by-layer assembly of ultrathin composite films from micron-sized graphite oxide sheets and polycations, Chem Mater 11(3) (1999) 771-778.

[4] Y.W. Zhu, W.W. Cai, R.D. Piner, A. Velamakanni, R.S. Ruoff, Transparent self-assembled films of reduced graphene oxide platelets, Appl Phys Lett 95(10) (2009).

[5] G. Eda, G. Fanchini, M. Chhowalla, Large-area ultrathin films of reduced graphene oxide as a transparent and flexible electronic material, Nature Nanotechnology 3(5) (2008) 270-274.

[6] D.A. Dikin, S. Stankovich, E.J. Zimney, R.D. Piner, G.H.B. Dommett, G. Evmenenko, S.T. Nguyen, R.S. Ruoff, Preparation and characterization of graphene oxide paper, Nature 448(7152) (2007) 457460.

[7] N.V. Medhekar, A. Ramasubramaniam, R.S. Ruoff, V.B. Shenoy, Hydrogen Bond Networks in Graphene Oxide Composite Paper: Structure and Mechanical Properties, Acs Nano 4(4) (2010) 2300 2306.

[8] J.M. Zhu, L.W. Zhu, Z.F. Lu, L. Gu, S.L. Cao, X.B. Cao, Selectively Expanding Graphene Oxide Paper for Creating Multifunctional Carbon Materials, J Phys Chem C 116(43) (2012) 23075-23082. 
[9] A. Clauss, U. Hofmann, Graphitoxyd-Membranen Zur Messung Des Wasserdampf-Partialdruckes, Angewandte Chemie-International Edition 68(16) (1956) 522-522.

[10] C.M. Chen, Q.H. Yang, Y.G. Yang, W. Lv, Y.F. Wen, P.X. Hou, M.Z. Wang, H.M. Cheng, SelfAssembled Free-Standing Graphite Oxide Membrane, Adv Mater 21(29) (2009) 3007-+.

[11] Z.T. Luo, Y. Lu, L.A. Somers, A.T.C. Johnson, High Yield Preparation of Macroscopic Graphene Oxide Membranes, J Am Chem Soc 131(3) (2009) 898-+.

[12] M. Krueger, S. Berg, D. Stone, E. Strelcov, D.A. Dikin, J. Kim, L.J. Cote, J.X. Huang, A. Kolmakov, Drop-Casted Self-Assembling Graphene Oxide Membranes for Scanning Electron Microscopy on Wet and Dense Gaseous Samples, Acs Nano 5(12) (2011) 10047-10054.

[13] R.R. Nair, H.A. Wu, P.N. Jayaram, I.V. Grigorieva, A.K. Geim, Unimpeded Permeation of Water Through Helium-Leak-Tight Graphene-Based Membranes, Science 335(6067) (2012) 442-444.

[14] R. Liu, G. Arabale, J. Kim, K. Sun, Y. Lee, C. Ryu, C. Lee, Graphene oxide membrane for liquid phase organic molecular separation, Carbon 77 (2014) 933-938.

[15] H. Li, Z. Song, X. Zhang, Y. Huang, S. Li, Y. Mao, H.J. Ploehn, Y. Bao, M. Yu, Ultrathin, MolecularSieving Graphene Oxide Membranes for Selective Hydrogen Separation Science 342(6154) (2013) 9598.

[16] H.W. Kim, H.W. Yoon, S.-M. Yoon, A. B.K., C. Y.H., H.J. Shin, H. Yang, U. Paik, S. Kwon, J.-Y. Choi, H.B. Park, Slective gas transport trough few-layered graphene and graphene oxide membranes, Science 342(6154) (2013) 91-95.

[17] H.L. Poh, F. Sanek, A. Ambrosi, G.J. Zhao, Z. Sofer, M. Pumera, Graphenes prepared by Staudenmaier, Hofmann and Hummers methods with consequent thermal exfoliation exhibit very different electrochemical properties, Nanoscale 4(11) (2012) 3515-3522.

[18] A.V. Talyzin, S.M. Luzan, T. Szabo, D. Chernyshev, V. Dmitriev, Temperature dependent structural breathing of hydrated graphite oxide in H2O, Carbon 49(6) (2011) 1894-1899.

[19] S.J. You, B. Sundqvist, A.V. Talyzin, Enormous Lattice Expansion of Hummers Graphite Oxide in Alcohols at Low Temperatures, Acs Nano 7(2) (2013) 1395-1399.

[20] A.V. Talyzin, T. Hausmaninger, S.J. You, T. Szabo, The structure of graphene oxide membranes in liquid water, ethanol and water-ethanol mixtures, Nanoscale 6(1) (2014) 272-281.

[21] A. Klechikov, J.C. Yu, D. Thomas, T. Sharifi, A.V. Talyzin, Structure of graphene oxide membranes in solvents and solutions, Nanoscale 7(37) (2015) 15374-15384.

[22] Y.P. Tang, D.R. Paul, T.S. Chung, Free-standing graphene oxide thin films assembled by a pressurized ultrafiltration method for dehydration of ethanol, J Membrane Sci 458 (2014) 199-208. [23] A. Vorobiev, A. Dennison, D. Chernyshov, V. Skrypnychuk, D. Barbero, A.V. Talyzin, Graphene oxide hydration and solvation: an in situ neutron reflectivity study, Nanoscale 6(20) (2014) 1215112156.

[24] W.S. Hummers, R.E. Offeman, Preparation of Graphitic Oxide, Journal of the American Chemical Society 80(6) (1958) 1339-1339.

[25] B.C. Brodie, On the Atomic Weight of Graphite, Philosophical Transactions of the Royal Society of London 149 (1859) 249-259.

[26] H.P. Boehm, W. Scholz, Der Verpuffungspunkt Des Graphitoxids, Zeitschrift Fur Anorganische Und Allgemeine Chemie 335(1-2) (1965) 74-\&.

[27] S.J. You, S.M. Luzan, T. Szabo, A.V. Talyzin, Effect of synthesis method on solvation and exfoliation of graphite oxide, Carbon 52 (2013) 171-180.

[28] S.J. You, S. Luzan, J.C. Yu, B. Sundqvist, A.V. Talyzin, Phase Transitions in Graphite Oxide Solvates at Temperatures Near Ambient, J Phys Chem Lett 3(7) (2012) 812-817.

[29] A.V. Talyzin, A. Klechikov, M. Korobov, A.T. Rebrikova, N.V. Avramenko, M.F. Gholami, N. Severin, J.P. Rabe, Delamination of graphite oxide in a liquid upon cooling, Nanoscale 7(29) (2015) $12625-12630$.

[30] S.J. You, J.C. Yu, B. Sundqvist, L.A. Belyaeva, N.V. Avramenko, M.V. Korobov, A.V. Talyzin, Selective Intercalation of Graphite Oxide by Methanol in Water/Methanol Mixtures, J Phys Chem C 117(4) (2013) 1963-1968. 
[31] A.Y.S. Eng, C.K. Chua, M. Pumera, Refinements to the structure of graphite oxide: absolute quantification of functional groups via selective labelling, Nanoscale 7(47) (2015) 20256-20266. [32] C. Botas, P. Alvarez, P. Blanco, M. Granda, C. Blanco, R. Santamaria, L.J. Romasanta, R. Verdejo, M.A. Lopez-Manchado, R. Menendez, Graphene materials with different structures prepared from the same graphite by the Hummers and Brodie methods, Carbon 65 (2013) 156-164.

[33] H.P. Boehm, A. Clauss, G. Fischer, C. Hofmann, Surface properties of extremely thin graphite lamellae, Proc. 5th Conf. on Carbon (Oxford: Pergamon) (1962) 73-80.

[34] T. Szabo, O. Berkesi, P. Forgo, K. Josepovits, Y. Sanakis, D. Petridis, I. Dekany, Evolution of surface functional groups in a series of progressively oxidized graphite oxides, Chem Mater 18(11) (2006) 2740-2749.

[35] A.V. Talyzin, V.L. Solozhenko, O.O. Kurakevych, T. Szabo, I. Dekany, A. Kurnosov, V. Dmitriev, Colossal Pressure-Induced Lattice Expansion of Graphite Oxide in the Presence of Water, Angewandte Chemie-International Edition 47(43) (2008) 8268-8271.

[36] A.V. Talyzin, B. Sundqvist, T. Szabo, I. Dekany, V. Dmitriev, Pressure-Induced Insertion of Liquid Alcohols into Graphite Oxide Structure, Journal of the American Chemical Society 131(51) (2009) 18445-18449.

[37] A.V. Talyzin, B. Sundqvist, T. Szabo, V. Dmitriev, Structural Breathing of Graphite Oxide Pressurized in Basic and Acidic Solutions., Journal of Physical Chemistry Letters 2(4) (2011) 309-313. [38] S.J. You, J.C. Yu, B. Sundqvist, A.V. Talyzin, Solvation of graphite oxide in water-methanol binary polar solvents, Phys Status Solidi B 249(12) (2012) 2568-2571.

[39] A. Klechikov, G. Mercier, T. Sharifi, I.A. Baburin, G. Seifert, A.V. Talyzin, Hydrogen storage in high surface area graphene scaffolds, Chem Commun 51(83) (2015) 15280-15283.

[40] B. Watts, L. Thomsen, P.C. Dastoor, Methods in carbon K-edge NEXAFS: Experiment and analysis, J Electron Spectrosc 151(2) (2006) 105-120.

[41] B. Watts, H. Ade, A simple method for determining linear polarization and energy calibration of focused soft X-ray beams, J Electron Spectrosc 162(2) (2008) 49-55.

[42] A. Hunt, D.A. Dikin, E.Z. Kurmaev, T.D. Boyko, P. Bazylewski, G.S. Chang, A. Moewes, Epoxide Speciation and Functional Group Distribution in Graphene Oxide Paper-Like Materials, Adv Funct Mater 22(18) (2012) 3950-3957.

[43] T. Gong, D.V. Lam, R. Liu, S. Won, Y. Hwangbo, S. Kwon, J. Kim, K. Sun, J.H. Kim, S.M. Lee, C. Lee, Thickness Dependence of the Mechanical Properties of Free-Standing Graphene Oxide Papers, Adv Funct Mater 25(24) (2015) 3756-3763.

[44] M.V. Korobov, A.V. Talyzin, A.T. Rebrikova, E.A. Shilayeva, N.V. Avramenko, A.N. Gagarin, N.B. Ferapontov, Sorption of polar organic solvents and water by graphite oxide: Thermodynamic approach, Carbon 102 (2016) 297-303.

[45] B. Rezania, N. Severin, A.V. Talyzin, J.P. Rabe, Hydration of Bilayered Graphene Oxide, Nano Lett 14(7) (2014) 3993-3998.

[46] A.G. Klechikov, G. Mercier, P. Merino, S. Blanco, C. Merino, A.V. Talyzin, Hydrogen storage in bulk graphene-related materials, Micropor Mesopor Mat 210 (2015) 46-51.

[47] K. Erickson, R. Erni, Z. Lee, N. Alem, W. Gannett, A. Zettl, Determination of the Local Chemical Structure of Graphene Oxide and Reduced Graphene Oxide, Adv Mater 22(40) (2010) 4467-4472.

[48] K.P. Loh, Q.L. Bao, G. Eda, M. Chhowalla, Graphene oxide as a chemically tunable platform for optical applications, Nat Chem 2(12) (2010) 1015-1024.

[49] S. Stankovich, D.A. Dikin, R.D. Piner, K.A. Kohlhaas, A. Kleinhammes, Y. Jia, Y. Wu, S.T. Nguyen, R.S. Ruoff, Synthesis of graphene-based nanosheets via chemical reduction of exfoliated graphite oxide, Carbon 45(7) (2007) 1558-1565.

[50] O.C. Compton, B. Jain, D.A. Dikin, A. Abouimrane, K. Amine, S.T. Nguyen, Chemically Active Reduced Graphene Oxide with Tunable C/O Ratios, Acs Nano 5(6) (2011) 4380-4391.

[51] A. Ganguly, S. Sharma, P. Papakonstantinou, J. Hamilton, Probing the Thermal Deoxygenation of Graphene Oxide Using High-Resolution In Situ X-ray-Based Spectroscopies, J Phys Chem C 115(34) (2011) 17009-17019. 
[52] H.Y. He, T. Riedl, A. Lerf, J. Klinowski, Solid-state NMR studies of the structure of graphite oxide, J Phys Chem-Us 100(51) (1996) 19954-19958.

[53] W. Gao, L.B. Alemany, L.J. Ci, P.M. Ajayan, New insights into the structure and reduction of graphite oxide, Nat Chem 1(5) (2009) 403-408.

[54] D. Pacile, J.C. Meyer, A.F. Rodriguez, M. Papagno, C. Gomez-Navarro, R.S. Sundaram, M. Burghard, K. Kern, C. Carbone, U. Kaiser, Electronic properties and atomic structure of graphene oxide membranes, Carbon 49(3) (2011) 966-972.

[55] V. Lee, R.V. Dennis, B.J. Schultz, C. Jaye, D.A. Fischer, S. Banerjee, Soft X-ray Absorption Spectroscopy Studies of the Electronic Structure Recovery of Graphene Oxide upon Chemical Defunctionalization, J Phys Chem C 116(38) (2012) 20591-20599.

[56] P. Feicht, R. Siegel, H. Thurn, J.W. Neubauer, M. Seuss, T. Szabo, A.V. Talyzin, C. Halbig, S. Eigler, D.A. Kunz, A. Fery, G. Papastavrou, J. Senker, J. Breu, Graphene Oxide: Mixing Apples and Oranges in the same Basket, submitted (2016). 